\title{
Avaliação de um Programa Psicoeducativo Preventivo para Cuidadores de Bebês
}

\author{
Evaluation of a Preventive Psycho-Educational Program for Baby Caregivers \\ Evaluación de un Programa Psicoeducativo Preventivo para Cuidadores de Bebés
}

\author{
Pâmella Batista de Souza ${ }^{1}$ \\ Universidade Federal de Santa Catarina \\ Ana Priscila Batista \\ Caroline Guisantes de Salvo Toni \\ Universidade Estadual do Centro-Oeste
}

\begin{abstract}
Resumo
Programas preventivos de saúde buscam agir com menores custos e alcançar efeitos positivos em longo prazo. Este artigo realizou a avaliação de um programa de orientação a cuidadores de bebês, que teve como foco a interação positiva e a prevenção de maus-tratos. Participaram 50 cuidadores, que responderam a um questionário, aplicado antes e após a participação no programa. Os dados foram analisados com auxílio do programa Statistical Package for the Social Sciences 18.0 (SPSS), em que foi verificada a normalidade dos dados e utilizado o teste de Wilcoxon. Entre as 27 questões, 15 tiveram diferenças estatisticamente significativas referentes às concepções de práticas adequadas. As questões que não indicaram diferenças significativas referiam-se aos cuidados que possivelmente já eram realizados pelos cuidadores. Os resultados evidenciam que o programa foi eficaz em seu objetivo de atuar enquanto prevenção primária e levar informações relevantes sobre o tema a um público amplo.
\end{abstract}

Palavras-chave: prevenção primária, Psicologia, promoção da saúde

\begin{abstract}
Preventive health programs seek to act at lower costs and achieve positive long-term effects. This article evaluated an orientation program for caregivers of infants, focusing on positive interaction and prevention of maltreatment. Fifty caregivers participated, who answered a questionnaire, applied before and after participating in the program. The data were analyzed with Statistical Package for the Social Sciences 18.0 (SPSS), where the normality of the data was verified and the Wilcoxon test was used. Among the 27 questions, 15 had statistically significant differences about the conceptions of proper practices. The questions that did not show significant differences were related to the care that the caregivers might have already performed. The results show that the program was effective in its goal of acting as primary prevention and bringing relevant information on the subject to a broad audience.
\end{abstract}

$$
\text { Keywords: primary prevention, Psychology, health promotion }
$$

\section{Resumen}

Los programas preventivos de salud buscan actuar con menores costos y alcanzar efectos positivos a largo plazo. Este artículo realizó la evaluación de un programa de orientación a los cuidadores de bebés, que tuvo como foco la interacción positiva y la prevención de malos tratos. Participaron 50 cuidadores, que respondieron a un cuestionario, aplicado antes y después de la participación en el programa. Los datos fueron analizados con ayuda del programa Statistical Package for the Social Sciences 18.0 (SPSS), donde se verificó la normalidad de los datos y se utilizó la prueba de Wilcoxon. Entre las 27 preguntas, 15 tuvieron diferencias estadísticamente significativas con respecto a las concepciones de prácticas adecuadas. Las cuestiones que no indicaron diferencias significativas se referían a los cuidados que posiblemente ya eran realizados por los cuidadores. Los resultados evidencian que el programa fue eficaz en su objetivo de actuar como prevención primaria y llevar informaciones relevantes sobre el tema a un público amplio.

Palabras clave: prevención primaria, Psicología, promoción de la salud

\footnotetext{
${ }^{1}$ Endereço de contato: Rua Adão Pinto Guimarães, 180, Guarapuava, Paraná, CEP 85025-330. E-mail: pamella.psi@hotmail.com
} 


\section{Conceitualização do tema e problema}

Prevenção e Promoção são áreas de estudo e formas de atuação ligadas às áreas da saúde. Enquanto Prevenção corresponde a medidas educativas para diminuição de fatores de risco, Promoção refere-se ao aumento de fatores de proteção. Os benefícios de ações preventivas, especificamente, ocorrem também no âmbito da saúde mental e diversas pesquisas demonstram a eficácia e efetividade de tais intervenções. Além disto, o custo de ambos é inferior ao de remediação (Abreu, Miranda, \& Murta, 2016; Melnick, \& Atallah, 2011; Murta et al., 2015; Paim, 2009), sendo esse um dos principais motivos pelos quais essa área tem crescido. Questão relevante é que alguns autores, como Buss (2009), afirmam que, quando executadas de maneira combinada, Promoção e Prevenção têm seus efeitos potencializados, o que justifica iniciativas que priorizam ambas as estratégias.

Os assuntos abrangidos por essa forma de fazer e pensar saúde são diversificados, sendo também desenvolvidos em contextos como escolas, hospitais e universidades, de forma a obter diferentes formatos e alcançar diferentes públicos (Abreu, Miranda \& Murta, 2016). A Psicologia] tem se apropriado dos princípios teóricos e práticos da Prevenção e Promoção, embora de maneira recente (Lohr, Pereira, Andrade, \& Kirchner, 2007, Murta et al, 2015, Zamberlan, 2003) e também tais avanços já estão expostos na literatura como em Lohr (2001), Alvarenga (2001), Murta et al (2015), Fernandes, Alckmin-Carvalho, Izbicki, e Melo (2014) e Abreu et al. (2016).

Um dos possíveis grupos participantes de estratégias pautadas em Promoção e Prevenção é formado por cuidadores de bebês e crianças (Murta, 2007; Flay et al, 2005). Com essa população, é possível desenvolver estratégias de manejo de contingências viabilizando um momento de reflexão e de contato com práticas educativas saudáveis, de forma a demonstrar, por exemplo, a necessidade de estarem atentos aos sinais dos bebês e de oferecerem respostas adequadas aos seus comportamentos. A aprendizagem em tais momentos pode ser generalizada para seus contextos e relações cotidianas. Com isso, há também a possibilidade de se evitar que comportamentos indesejáveis e inadequados por parte dos cuidadores sejam instalados, buscando assim eliminar fatores de risco (Mondin, 2008; Pinheiro, \& Haase, 2012).

Programas desse cunho partem do conhecimento de que o desenvolvimento infantil é afetado por diversos fatores, tais como biológicos, culturais, relacionais e sociais, e que, quanto aos dois últimos, o meio familiar ganha destaque, uma vez que é o primeiro e mais importante contexto de interação e aprendizagem da criança (Caminha, Caminha, \& Dutra, 2017; Mondin, 2008; Papalia, \& Feldman, 2013). Desse modo, o ambiente familiar é visto como primordial para o desenvolvimento do ser humano (Paula, Pires, Mascarenhas, Costa, \& Brito, 2013; Weber, 2008).

De modo mais específico, a interação entre o cuidador e o seu bebê é fundamental, pois é a partir dela que este se desenvolve de forma biopsicossocial (Bee, 2011; Papalia, \& Feldman, 2013; Weber, 2008). A extrema importância da relação cuidador-bebê refere-se ao fato de que os cuidadores têm influência no desenvolvimento da criança, sendo modelos de aprendizagem e fonte de afeto. Por esses motivos, a interação positiva entre cuidador e criança é essencial, sendo a demonstração de afeto, as vivências e as práticas educacionais positivas fundamentais para a autoconfiança e o desenvolvimento saudável da criança (Caminha, Almeida, \& Scherer, 2011; Bolsoni-Silva, Silveira, \& Ribeiro, 2008; Lubi, 2003). 
Sabe-se que algumas maneiras inadequadas e prejudiciais podem estar presentes em algumas práticas educativas, como práticas coercitivas e de punição física (Cecconello, Antoni, \& Koller, 2003; Weber, Viezzer, \& Branderburg, 2003). Tais práticas educativas ainda são comuns em nossa realidade cultural como uma espécie de justificativa aos comportamentos infantis vistos como inadequados (Brazelton \& Greespan, 2002; Carmo \& Alvarenga, 2012). No entanto o fato é que práticas como essas podem gerar apego inseguro e ambivalente em bebês, além de prejuízos físicos, como é o caso da síndrome do bebê sacudido, ocasionada quando os pais ou cuidadores chacoalham a criança com força e assim podem gerar o chamado "efeito chicote", causando danos como vômitos e convulsões, além de cegueira e deficiência cognitiva em longo prazo (Lopes, 2013).

Por tratar-se de um tema amplo, diversos programas e estratégias têm surgido buscando auxiliar pais e cuidadores na relação com suas crianças. Programas voltados a esse público ocorrem tanto de maneira preventiva quanto como promoção de saúde e buscam fornecer um conjunto de serviços e apoios necessários para responder às necessidades das crianças e de suas famílias. Esses programas mostram-se como de baixo custo e com formatos breves (Bolsoni-Silva, Silveira, \& Ribeiro, 2008). Um exemplo são as intervenções pautadas em psicoeducação que contribuem para o desenvolvimento e previnem eventuais problemas (Abreu, Barletta, \& Murta, 2015; Haase, Kappler, \& Schaefer, 2000; Pardo \& Carvalho, 2011).

Uma das iniciativas desse cunho que é desenvolvida no Brasil é o Programa Cuida Bem: Interação Positiva Cuidador-Bebê e Prevenção a Maus Tratos. Tal programa acontece em uma clínica-escola de Psicologia e Fonoaudiologia de uma universidade estadual da região centro-sul do Paraná. O programa visa fornecer a pais e cuidadores informações sobre desenvolvimento infantil, sobretudo assuntos relacionados a sono, alimentação, rotina e exemplos de práticas educativas saudáveis. O programa também expõe sobre os danos do uso de punições físicas, tais como o de chacoalhar o bebê, que podem acarretar síndrome do bebê sacudido (Lopes, 2013; Schavarem et al, 2016; Souza, Batista, \& Toni, 2018).

A literatura tem demonstrado a importância de avaliação e publicação de dados sobre programas preventivos dirigidos a cuidadores de crianças (Abreu, Miranda \& Murta, 2016; Murta, 2007). Um dos programas desse cunho é o Programa Cuida Bem, em que seus procedimentos foram delineados e explicados, conforme consta em Souza, Batista \& Toni (2018) e Scharavem et al (2016). No entanto ainda são poucos os estudos brasileiros que descrevem a implementação de programas preventivos e os analisam em termos de efetividade (Murta 2007), o que justifica a execução desta pesquisa.

A partir do exposto, evidencia-se a relevância da Promoção e Prevenção de saúde na Psicologia, sobretudo quando direcionado a pais e cuidadores de bebês, a fim de levar informações de temas pertinentes ao desenvolvimento infantil. Da mesma forma, salienta-se a importância da análise de iniciativas com tais características e objetivos. Nesse contexto, este artigo visa apresentar os resultados da avaliação do programa Cuida Bem, que teve como foco a interação positiva e a prevenção de maus-tratos. 


\section{Método}

\section{Caracterização da amostra}

Participaram desta pesquisa 50 participantes do Programa Cuida Bem, de ambos os sexos, sendo 42 do sexo feminino e oito do sexo masculino, o que representa $84 \%$ e $8 \%$, respectivamente, da amostra total. A idade variou entre 13 e 54 anos.

Os participantes foram selecionados a partir do seguinte critério de inclusão: serem pais ou cuidadores de crianças de até dois anos. Como exclusão, os critérios foram: ser acompanhante dos pais ou responsáveis pela criança e a criança ter mais que dois anos de idade.

\section{Local}

O local de coleta foi o mesmo onde o Programa Cuida Bem é realizado, em uma clínica-escola de fonoaudiologia e psicologia de uma universidade estadual da Região Centro-Sul do Paraná.

\section{Instrumento}

Foi utilizado um questionário confeccionado pelas autoras, o qual contava com 37 questões, sendo 10 delas sobre dados sociodemográficos e 27 divididas em duas sessões. Na primeira sessão (13 questões), eram apresentadas possibilidades de ações a serem feitas na hora do choro e na hora da alimentação, em que o participante respondia com qual frequência faria cada uma, sendo as opções de resposta "Nunca", "Quase Nunca", "Às vezes", "Quase Sempre" e Sempre". Na segunda sessão (14 questões), o participante devia responder o quanto considerava importante sentenças sobre o desenvolvimento do bebê, em uma escala de 0 a 5 , sendo 0 pouco importante e 5 muito importante.

O questionário visava compreender duas principais questões: 1) o perfil sociodemográfico dos participantes e 2) comparar as respostas obtidas nas 27 questões antes e após a participação na orientação e de tal modo compreender, respectivamente, 2.1) as opiniões e crenças iniciais dos participantes sobre os assuntos abordados e 2.2) o efeito da intervenção sobre as respostas dos participantes ao questionário.

\section{Procedimentos de coleta de dados}

A coleta de dados ocorreu em dois momentos: antes e após a participação do cuidador no Programa Cuida Bem. Após os participantes terem aceitado participar do programa, eles também foram convidados a participar da pesquisa. Na sequência, era entregue o Termo de Consentimento Livre e Esclarecido para ser lido e assinado, caso concordassem em participar. A coleta de dados ocorreu no formato individual. As pesquisadoras se certificavam de que não havia dúvidas por parte dos participantes sobre o instrumento e então eles o preenchiam.

A duração na participação da pesquisa era de em torno de uma hora, no momento de orientação aos cuidadores que ocorria enquanto eles aguardavam na fila de espera para realizar o teste da orelhinha em seus filhos na Clínica-Escola. 


\section{Análise de dados}

Os dados foram expressos em termos numéricos e estatísticos e a análise foi realizada com o programa Statistical Package for the Social Sciences 18.0 (SPSS), em que foi verificada a normalidade dos dados e utilizado o teste de Wilcoxon para comparação das respostas ao questionário, antes e após a participação no programa. Já as questões referentes aos dados sociodemográficos foram analisadas a partir da Estatística Descritiva Básica.

\section{Aspectos éticos}

O presente estudo foi submetido ao Comitê de Ética em Pesquisa com Seres Humanos e Animais da Universidade Estadual do Centro-Oeste e obteve parecer favorável à sua realização, número 1.111.349, o que demonstra que obedece à Resolução 466/2012.

\section{Resultados}

Para fins didáticos, primeiramente estão apresentados os dados referentes aos dados sociodemográficos dos participantes e, na sequência, os dados obtidos com a aplicação do instrumento.

Em relação aos dados sociodemográficos dos participantes, a idade variou entre 13 e 54 anos, sendo que a maior parte da amostra $(n=34)$ tinha entre 21 e 35 anos. Em relação ao estado civil, o mais frequente era o item Casado ou União Estável $(n=30)$, o que representa $60 \%$ dos participantes. Na sequência, aparece a opção Solteiro $(n=12)$, correspondente a $24 \%$ dos participantes, enquanto as opções Divorciado e Outro foram assinaladas por 2 (4\%) e 6 (12\%) participantes, respectivamente.

Quanto à escolaridade, as opções mais assinaladas foram a de Ensino Médio Completo $(n=14)$, Ensino Fundamental Incompleto $(n=13)$ e Ensino Fundamental Completo $(n=12)$ (sendo que 11 não responderam). Em relação à profissão, observou-se que a maioria dos participantes ocupava a profissão de agricultor $(n=17)$ e do $\operatorname{lar}(n=15)$, representando, assim, 64\% do total da amostra. As profissões como vendedor, babá, auxiliar administrativo e professor foram representadas por dois participantes cada uma. Já a profissão do(a) companheiro(a) foi bastante diversificada, de modo que o que se sobressai é a profissão de agricultor $(n=18)$, representando $36 \%$ do total.

Em relação ao número de pessoas com quem o cuidador morava: a maioria dos participantes ( $n=18$ ) morava com duas pessoas, já 12 deles moravam com quatro pessoas e oito cuidadores moravam com cinco pessoas. Na opção sobre com quem o bebê ficava a maior parte do tempo, a maioria $(n=46)$ assinalou que era com a mãe e algumas opções, como mães e familiares, foram assinaladas pelas outras quatro pessoas.

Verificou-se que 23 (46\%) participantes vivenciavam a chegada do primeiro filho. Os outros 27 participantes (54\%) já tinham mais filhos, sendo que, desses, 13 tinham mais um, 12 tinham mais dois, enquanto um tinha mais três filhos e outro tinha mais cinco filhos. Sobre os meses do bebê no dia da coleta de dados, 36 bebês (72\%) tinham por volta de um mês, sendo 20 deles com menos de um mês e 16 entre um mês e dois meses de idade. Também houve bebês com 2 meses $(n=4), 5$ meses $(n=2)$, e acima de seis meses houve oito bebês (16\%). 
Com relação às questões acerca do desenvolvimento infantil e maus-tratos a bebês antes e após participação no Programa Cuida Bem, observa-se, conforme a Tabela 1, a média das respostas dos participantes às questões do questionário.

Tabela 1

Respostas que obtiveram resultado estatisticamente significativo em comparação com o pré-teste

\begin{tabular}{|c|c|c|c|c|c|}
\hline \multirow{2}{*}{ Bloco } & \multirow{2}{*}{$\begin{array}{l}\text { Itens estatisticamente significativos } \\
\qquad(p<0,05)\end{array}$} & \multicolumn{2}{|c|}{ Média de resposta } & \multirow{2}{*}{$\begin{array}{l}\text { Valor } \\
\text { de Z }\end{array}$} & \multirow{2}{*}{$\begin{array}{l}\text { Valor } \\
\text { de } p\end{array}$} \\
\hline & & Antes & Após & & \\
\hline \multirow{5}{*}{ a) } & Oferecer uma nova mamada ou uma chupeta & 4,10 & 4,40 & 1,942 & 0,050 \\
\hline & Cantar para ele até que ele pare & 3,48 & 4,14 & 3,992 & 0,000 \\
\hline & $\begin{array}{l}\text { Pedir para alguém ficar com o bebê e sair de } \\
\text { perto para me acalmar }\end{array}$ & 1,34 & 2,86 & 3,256 & 0,0500 \\
\hline & Ligar para algum profissional & 2,04 & 2,92 & 3,857 & 0,030 \\
\hline & Chacoalhar o bebê até que ele pare & 2,48 & 1,24 & 1,587 & 0,000 \\
\hline \multirow{5}{*}{ b) } & Procurar um lugar calmo & 4,28 & 4,62 & 1,957 & 0,050 \\
\hline & Procurar ficar sozinho com o bebê & 3,46 & 3,96 & 3,077 & 0,030 \\
\hline & Procurar ler & 1,52 & 1,92 & 2,807 & 0,005 \\
\hline & Procurar assistir à televisão & 2,84 & 2,50 & 2,134 & 0,033 \\
\hline & $\begin{array}{c}\text { Procurar estar com outras pessoas para } \\
\text { conversar }\end{array}$ & 2,70 & 3,34 & 2,087 & 0,004 \\
\hline \multirow{5}{*}{ c) } & $\begin{array}{c}\text { Apresentar ao bebê os objetos e pessoas que } \\
\text { o rodeiam }\end{array}$ & 4,28 & 4,60 & 2,137 & 0,033 \\
\hline & $\begin{array}{c}\text { Colocar músicas infantis/instrumentais para } \\
\text { o bebê }\end{array}$ & 3,90 & 4,26 & 2,648 & 0,008 \\
\hline & Criar uma rotina para o bebê & 4,42 & 4,78 & 3,082 & 0,002 \\
\hline & $\begin{array}{c}\text { Deixar o bebê sozinho no berço/carrinho } \\
\text { quando acordado }\end{array}$ & 2,38 & 2,92 & 2,027 & 0,043 \\
\hline & Ficar a maior parte do tempo com a mãe & 4,70 & 4,68 & 5,909 & 0,000 \\
\hline
\end{tabular}

Legenda: Os blocos referem-se a situações fictícias e exemplares, sendo: a) Frequência com a qual o cuidador pretenderia agir para lidar com o choro incessante do bebê; b) frequência com a qual pretenderia realizar determinadas ações na hora da alimentação do bebê e c) grau de importância dada a questões sobre a relação cuidador-bebê e desenvolvimento infantil.

De maneira geral, percebeu-se que 15 questões (55,5\%) obtiveram médias com diferenças significativas quando comparadas às respostas antes e após a participação no programa, o que demonstra mudança no conhecimento dos cuidadores em relação aos conteúdos apresentados. Essas 15 questões foram distribuídas em três blocos, sendo referentes a: Bloco A. frequência com a qual o cuidador descreve agir para lidar com o choro incessante do bebê; Bloco B. frequência com a qual descreve realizar determinadas ações na hora da alimentação do bebê; e Bloco C. grau de importância dada a questões sobre a relação cuidador-bebê e desenvolvimento infantil.

Cabe destacar que, quanto aos valores das médias que são apresentadas, os valores mais próximos de um representam uma menor frequência ou importância e, quanto mais próximo de cinco, maior a frequência ou importância assinalada pelo cuidador. Os resultados de cada bloco são apresentados a seguir. 
Em relação ao Bloco A, foi observado que em quatro itens houve aumento na média das respostas dos participantes e em um houve diminuição, o que representa diferença estatisticamente significativa. No item "Oferecer uma nova mamada ou uma chupeta", houve um aumento na média das respostas, o que demonstra que as participantes já apresentavam uma média alta antes da intervenção. O mesmo aconteceu com o item "Cantar para ele até que ele pare", que já tinha uma frequência alta e aumentou ainda mais. O item "Pedir para alguém ficar com o bebê e sair de perto para me acalmar" aumentou no momento após a participação no programa. É possível traçar um paralelo entre essa questão e a questão "Ligar para algum profissional", que também obteve um aumento, passando, então, de mais próximo de "raramente" para "às vezes".

O item "Chacoalhar o bebê até que ele pare" teve uma diminuição em sua média de respostas, ou seja, antes ela era assinalada, em média, em algo entre "raramente" e "às vezes", passando para mais próximo de "nunca". O assunto sobre chacoalhar foi abordado nas orientações em termos de seus aspectos negativos, de diferenciação entre o embalar e o chacoalhar (Lopes, 2013) e visava, portanto, que os participantes compreendessem os aspectos negativos dessa ação e, consequentemente, passassem a diminuir sua frequência sobre como achavam que poderia agir diante do choro do bebê.

Nas questões do Bloco B, quatro questões aumentaram sua média e mostraram resultados estatísticos significativos, enquanto apenas uma diminuiu. A questão referente a "Procurar um lugar calmo" aumentou, o que demonstra que as mães já a concebiam como frequente, passando de "quase sempre" para "sempre", após conhecerem os benefícios que realizar a amamentação em local calmo e silencioso traz ao bebê - isso também permite poder estar sozinha com ele, questão importante para formação de vínculo entre mãe e bebê (Vinha, 2000). Ao estar sozinho(a) com a criança, o(a) cuidador(a) pode fazer atividades como ler/ ouvir música; a questão sobre "Procurar estar com outras pessoas para conversar" também obteve aumento estatístico significativo. Já a questão sobre assistir à televisão foi a única que teve sua média diminuída.

No Bloco C, em quatro itens houve aumento na média das respostas dos participantes e em um houve diminuição. As questões que obtiveram aumento quanto ao grau de importância foram: "Apresentar ao bebê os objetos e as pessoas que o rodeiam", "Colocar músicas infantis/instrumentais para o bebê", "Criar uma rotina para o bebê" e "Deixar o bebê sozinho no berço/carrinho quando acordado". A questão que sofreu diminuição nesse bloco foi a referente a "Ficar a maior parte do tempo com a mãe".

As outras 12 questões, que correspondem a 45,5\%, não obtiveram resultado relevante de mudança. Atribui-se isso ao fato, possivelmente, de que muitos cuidadores já haviam estabelecidos em seu cotidiano a frequência das ações mencionadas nas 12 questões. Um exemplo de prática frequente que sofreu pouca alteração é "Manter o contato visual quando falar com o bebê". Já um exemplo de prática pouco frequente e que sofreu pouca alteração foi a concepção sobre o bebê "Ficar a maior parte do tempo com outro cuidador".

\section{Discussão}

Em relação aos dados sociodemográficos, observou-se que a escolaridade dos participantes era em termos de $50 \%$ até o Ensino Fundamental ou até alguns anos antes de concluí-lo. 
Sobre esse assunto, pesquisas como a de Carmo e Alvarenga (2012) observaram que, quanto menor a escolaridade da mãe, maior é a frequência de utilização de punição física. Esse estudo aponta, entre outras conclusões, que o nível de escolaridade dos cuidadores é um preditor sociodemográfico ligado ao grau de qualidade de seus cuidados com seus filhos, além do conhecimento que possuem sobre desenvolvimento infantil. Consoante a isso, Fraga, Linhares, Carvalho e Martinez (2008), Silva, Nunes, Betti, Rios (2008) e Silva et al (2011) mostraram que a baixa escolaridade dos cuidadores é um fator de risco ao desenvolvimento da criança. A partir dessa perspectiva, compreende-se que o Programa Cuida Bem atuou junto a cuidadores com esse perfil de baixa escolaridade. Desta forma, infere-se que foi possível auxiliá-los na construção de informações e conhecimento sobre o tema de desenvolvimento infantil.

Outro dado significativo é referente ao fato de 18 cuidadores morarem com mais duas pessoas em sua casa, o que possibilitou compreender quantas pessoas conviviam com o bebê. Lopes (2013) assinala que famílias monoparentais ou onde há apenas um cuidador para o bebê é um fator de risco à SBS, no entanto, ao se ter mais de um cuidador, ambos podem dividir as funções de cuidar da criança.

Lopes (2013) aponta ainda que, quanto mais precoces as intervenções realizadas sobre a SBS, maior a chance de as informações repassadas atuarem como fator de proteção sobre à ocorrência da SBS, pois os bebês geralmente são mais sacudidos entre o 4 ㅇ e 6ㅇ mês de vida, em média, e o cuidador que passou por orientação anterior a esse momento tem as informações a respeito. Assim, é possível perceber que o programa atingiu a população mais indicada para intervenções com a mesma finalidade.

O fato de a maior parte dos cuidadores assinalarem que o bebê ficava com a mãe está possivelmente interligado com o fato de que $64 \%$ também assinalaram ter a profissão de agricultor e do lar, ou seja, profissões que possibilitam estar por um período mais prolongado com os bebês. Outro fator é que, como os bebês eram na maioria recém-nascidos, as mães ainda estavam em período de licença-maternidade e em período integral com os filhos. Além disso, sabe-se que é atribuído culturalmente, na maioria das famílias, que o cuidado da criança seja realizado, primordialmente, pela figura materna. Assim, embora pesquisas como a de Weber (2008) destaquem que a configuração familiar e a distribuição de seus afazeres estejam se modificando, a maior parte dos participantes da pesquisa mantinha uma estrutura e configuração de família nuclear.

Sobre as questões acerca do desenvolvimento infantil e maus-tratos a bebês antes e após participação no Programa Cuida Bem, as questões do Bloco A evidenciam um aumento significativo estaticamente nas médias das questões referentes à participante se distanciar do bebê na hora do choro para ligar para um profissional ou simplesmente para poder se acalmar, o que demonstra o quanto as participantes inicialmente não consideravam tal questão como possível e que, após participar do programa, puderam ver os possíveis benefícios dessa estratégia. Também se considera que as participantes possam ter naturalizado o cuidado do bebê como responsabilidade apenas da figura materna (Weber, 2008) e, por isso, apresentavam dificuldade de conceber se distanciar da criança em momentos que isso poderia ser necessário para se acalmar, como em horas de choro incessantes da criança, o que configura fator de proteção para a SBS (Lopes, 2013). 
Nos momentos das orientações, foi possível perceber resistência por parte dos cuidadores, em sua maioria mães, em pensar na possibilidade de pedir ajuda para algum outro cuidador do bebê ou mesmo um profissional. Apesar disso, a mudança de resposta de "nunca" para "raramente" na pergunta referente a "Pedir para alguém ficar com o bebê e sair de perto dele" (na hora do choro) indica uma possível flexibilidade e cogitação quanto a essa ação.

Os três fatores (sair de perto do bebê; se acalmar e pedir ajuda a um profissional) caracterizam-se como fatores de proteção à síndrome do bebê sacudido (SBS), pois a ação de pedir para alguém ficar com o bebê possibilita que o cuidador principal possa se distanciar (Lopes, 2013). Como o estresse com o choro é uma das principais causas de chacoalhar uma criança, acalmar-se é sempre uma boa opção. Além disso, pedir ajuda a um profissional é dividir a ansiedade, o medo e a preocupação com o bem-estar da criança com mais pessoas. Ou seja, essas três ações trazem benefícios aos próprios cuidadores e à criança, que pode ser protegida de ser eventualmente chacoalhada.

Segundo Lopes (2013), a diminuição significativa da intenção dos participantes de chacoalharem seus bebês quando chorarem por muito tempo revela o aprendizado obtido nas orientações. Nessa direção, os dados da presente pesquisa mostraram um aumento na frequência com que os participantes buscariam fazer ações mais saudáveis que pudessem diminuir o choro da criança, tais como oferecer uma nova mamada ou chupeta e cantar para o bebê.

Em relação aos dados do Bloco $B$, as questões do momento da amamentação também obtiveram resultado significativo e podem-se observar as questões sociais/interacionais atribuídas à amamentação, que tem como base a explicação biológica/nutricional comentada por Almeida (2004). Em termos sociais e interacionais, o ideal é que a amamentação possibilite contato entre mãe e bebê em um lugar calmo e é importante a mãe não realizar outras atividades nesse momento que prendam sua atenção (Brazelton, 1995; Vinha, 2000) como assistir à televisão. A sentença sobre as mães buscarem aproveitar o momento da amamentação para proximidade e criação de vínculo afetivo com os bebês demonstra a compreensão de um aspecto importante ressaltado na literatura por Brazelton (1995) e Bee (2011): é importante para os pais passarem tempo de qualidade com o bebê, isso se torna ainda mais imprescindível nos primeiros meses de vida da criança e possível em momentos como o da amamentação ou alimentação. Ao estarem sozinhos com seus bebês, a mãe ou o pai podem estar atentos aos sinais da criança (Papalia, \& Feldman, 2013). Já o aumento na frequência de buscarem estar em um lugar calmo com a criança e procurarem ler (visto que é uma atividade que não desprende total atenção da mãe) também revela maior compreensão e intenção de estar próximo à criança de maneira adequada.

Da mesma maneira, a diminuição na frequência de buscar assistir à televisão no momento da alimentação acompanha a mesma compreensão: é importante o cuidador aproveitar-se desse momento para o cuidado e contato com a criança (Brazelton, 1995, Vinha, 2000). Uma das possibilidades para o aumento estatístico na questão "Procurar estar com outras pessoas para conversar" é o fato de as mães lembrarem, ao assinalarem o segundo questionário, que moravam com várias pessoas e que, em alguns casos, sempre havia alguém perto para conversar, o que podia inviabilizar estar sozinha com a criança na hora da alimentação. No entanto era frisada a importância de momentos sozinha com a criança, salvo as exceções 
que variavam conforme o contexto e a rotina do participante. Assim, as orientações eram padronizadas na concordância da seguinte questão: tempo individual entre cuidador e criança é fundamental para a criação de vínculo entre ambos (Brazelton, 1995).

Nas questões do Bloco C, os participantes também relataram, após a orientação, a compreensão da importância de fazer mais a atividade de apresentar ao bebê pessoas e objetos. Esse item é visto como essencial para o desenvolvimento cognitivo e deve ser feito periodicamente, além de o adulto necessitar estar atento às reações do bebê nesse momento, tais como acenos, sorrisos etc. (Antunes, 2011; Papalia e Feldman, 2013; Brazelton, 1995).

Outra prática altamente benéfica e que obteve aumento significativo refere-se a "Colocar músicas infantis/instrumentais para o bebê", que ainda, conforme o mesmo autor, é uma fonte de estimulação do desenvolvimento dos sentidos dos bebês (audição), além de acalmar o bebê, e as músicas podem ser colocadas em momentos como o banho e antes de dormir.

O aumento na questão referente a buscar criar uma rotina para o bebê demonstra facilitar um aspecto importante apresentado por Brazelton (1995), França (2016) e Papalia e Feldman (2013): a criança criar previsibilidade, de maneira a saber o horário de mamar e de dormir, por exemplo. Para Brazelton (1995), é interessante criar uma rotina para o bebê para trazer benefícios tanto para a própria criança como para os cuidadores, pois com a rotina estabelecida o cuidador pode programar suas atividades diárias. Sobre esse assunto, pode-se perceber também que os pais relatavam suas dificuldades e facilidades, pedindo, nos primeiros casos, informações de como poderiam criar uma rotina para o bebê.

A diminuição na questão sobre ficar a maior parte do tempo com a mãe é explicada pela seguinte questão: nas orientações, era enfatizado o quanto é natural a mãe se sentir cansada e estressada em alguns momentos e, assim, pode contar com auxílio do pai ou outro cuidador da criança, além de profissionais. Com isso, as mães passaram a considerar tal questão, o que pode ser expresso pela diminuição da média de importância de acharem que a criança necessita ficar a maior parte do tempo somente com a mãe. Assim, aponta-se que as mães puderam ter mais clareza de que podem precisar de apoio.

Por último, a questão referente a deixar a criança sozinha no berço ou no carrinho pode ter aumentado pelo fato de os participantes terem mais conhecimento sobre a importância de a criança ter contato e interação com o ambiente a sua volta e da maneira correta de como fazer isso (Papalia; Feldman, 2013), deixando, assim, a resistência inicial, inclusive verbalizada, sobre o tema.

\section{Considerações Finais}

Este estudo teve como objetivo descrever os resultados da avaliação das contribuições de um programa psicoeducativo sobre desenvolvimento infantil, interação positiva cuidador-bebê e prevenção a maus-tratos voltados a cuidadores de bebês.

Pode-se perceber que a orientação aos cuidadores realizada em formato breve trouxe resultados satisfatórios, pois mais da metade das questões avaliadas apresentaram diferença estatisticamente significativa na comparação pré e pós-participação no programa. Assim, os resultados mostraram que a intervenção foi eficaz em propiciar conhecimento aos participantes sobre desenvolvimento infantil, interação saudável entre cuidador e bebê, além de informações sobre a SBS. 
Uma das limitações do estudo foi o fato de as questões contemplarem possibilidades de ação a partir de seus conhecimentos, quando dados mais precisos poderiam ser obtidos por meio de formatos que possibilitassem a observação de práticas do cotidiano dos participantes. Por esse motivo, sugerem-se novos estudos para que se possa, a partir de estratégias de observação direta, conhecer a repercussão da psicoeducação realizada a cuidadores. Outras limitações são referentes ao número baixo de participantes e amostra de estudo. Uma maior amostra de participantes poderia possibilitar um melhor nível de generalização.

A partir dos resultados, conclui-se que o Programa Cuida Bem realizou procedimentos voltados para a promoção e prevenção de saúde, uma vez que buscou atuar sobre a diminuição de fatores de risco ao bem-estar e desenvolvimento dos bebês, acrescentando conhecimento aos participantes sobre os efeitos de suas ações sobre os bebês, bem como buscou ampliar fatores de proteção, todos no âmbito de repasse de informações a um público específico.

\section{Referências}

Abreu, S., Miranda, A. P. V., \& Murta, S. G. (2016). Programas preventivos brasileiros: Quem Faz e como É Feita a Prevenção em Saúde Mental? Psico-USF, 21(1), 163-177.

Abreu, S., Barletta, J. B., \& Murta, S. G. (2015). Prevenção e promoção em saúde mental: pressupostos teóricos e marcos conceituais. In S. G. Murta, C. Leandro-França, K. B. Santos, \& L. Polejack, Prevenção e promoção em saúde mental: fundamentos, planejamento e Estratégias de intervenção (pp. 54-74). Novo Hamburgo: Sinopsys.

Almeida, J. A. G. (2004). Amamentação: um híbrido natureza-cultura. Jornal da Pediatria, 80(5), (pp. S219-S125).

Alvarenga, P. (2001). Práticas educativas parentais como forma de prevenção de problemas de comportamento. In Guilhardi, H. J., Madi, M. B. B. P., Queiroz, P. P., \& Scoz M. C. (Orgs.), Sobre comportamento e cognição: Expondo a variabilidade (pp. 54-60). Santo André: Esetec.

Antunes, C. (2011). Guia para estimulação do cérebro infantil: Do nascimento aos 3 anos. 2a ed. Petrópolis, RJ: Vozes.

Bee, H. (2011). A criança em desenvolvimento. Porto Alegre: Artes Médicas.

Brazelton, T. B. (1995). O grande livro da criança. Lisboa: Editorial Presença.

Brazelton, T.B., Greespan, S.I (2002). As necessidades essenciais da criança: o que toda criança precisa para crescer, aprender e se desenvolver. Porto Alegre: Artmed.

Caminha, R. M., Caminha, M. G., \& Dutra, C. A. (2017). A prática cognitiva na infância e na adolescência. Novo Hamburgo: Sinopsys, 768p.

Carmo, P. H. B., \& Alvarenga, P. (2012, Maio/Agosto). Práticas educativas coercitivas de mães de diferentes níveis socioeconômicos. Estudos de Psicologia. 17(2), 191-197.

Bolsoni-Silva, A. T., Silveira, F. F., \& Ribeiro, D. C. (2008). Avaliação dos efeitos de uma intervenção com mães/cuidadores: Contribuições do treinamento de habilidades sociais. Contextos Clínicos, 1(1), 19-27.

Buss, P. M. (2009). Uma Introdução ao Conceito de Promoção de Saúde. In D. Czeresnia, \& C. M. Freitas (2009). Promoção de Saúde: Conceitos, reflexões, tendências. 2a ed. Rio de Janeiro: Ed. Fiocruz. 
Caminha, M. G., Almeida, F. F., \& Scherer, L. P. (2011). Treinamento de pais: Fundamentos teóricos. In Caminha, M. G, \& Caminha, R. M. (Orgs.), Intervenções e treinamento de pais na clínica infantil (pp. 13-30). Porto Alegre: Sinopsys Editora.

Cecconello, R. M., De Antoni, A., \& Koller, S. H. (2003). Práticas educativas, estilos parentais e abuso físico no contexto familiar. Psicologia em Estudo, 8(n.e.), 45-50.

Fernandes, L. F. B., Alckmin-Carvalho, F., Izbicki, S., \& Melo, M. H. S. (2014, Setembro/ Dezembro). Prevenção universal de ansiedade na infância e adolescência: uma revisão sistemática. Revista Psicologia: Teoria e Prática, 16(3), 83-99. ISSN 1516-3687.

Flay, B. R., Biglan, A., Boruch, R., Castro, F. G., Gottfredson, D., Kellam, S., Ji, P. (2005). Standards of evidence: criteria for efficacy, effectiveness and dissemination. Prevention Science, 6(3), 151-175.

Fraga, D. A., Linhares, M. B. M., Carvalho, A. E. V., \& Martinez, F. E. (2008). Desenvolvimento de bebês nascidos pré-termo e indicadores emocionais maternos. Psicologia: Reflexão e Crítica, 21(1), 33-41.

França, J. L. (2016). Estimulação Precoce: Inteligência emocional e cognitiva de 0 a 6 anos. São Paulo: Cultural.

Haase, V. G., Kappler, C., \& Schaefer, S. A. Um modelo de intervenção psicoeducacional para prevenção da violência no ambiente familiar e escolar. (2000). In V. G. Haase, R. Rothe-Neves, C. Käppler, M. L. M. Teodoro, \& G. M. O. Wood (Orgs.). Psicologia do Desenvolvimento: Contribuições Interdisciplinares. (pp. 249-264). Belo Horizonte: Health.

Lohr, S. S. (2001). Desenvolvimento das habilidades sociais como forma de prevenção. In H. J. Guilhardi, M. B. B. P. Madi, P. P. Queiroz, \& M. C. Scoz. Sobre comportamento e cognição. Expondo a variabilidade (Vol. 8). (pp. 190-209). São Paulo: Esetec.

Lohr, S. S., Pereira, A. C. S., Andrade, A. L. M., \& Kirchner, L. F. (2007, Setembro/Dezembro). Avaliação de Programas Preventivos: Relatos de experiência. Revista Psicologia em Estudo, 12(3), p. 641-649.

Lopes, N. R. L. (2013). Trauma Craniano Violento: Conhecimento Parental e Avaliação de Material Informativo. Dissertação (Mestrado em Psicologia, Universidade Federal de São Carlos, São Carlos, SP).

Lubi, A. P. L. (2003). Estilo parental e comportamento socialmente habilidoso da criança com pares. In M. Z. Brandão, F. C. S. Conte, F. S. Brandão, Y. K. Ingberman, C. B. Moura, V. M. Silva, \& S. M. Oliane (Orgs.). Sobre comportamento e Cognição: As bases históricas e os avanços, a seleção por conseqüências em ação. pp. 536-541. Santo André: ESETec.

Mondin, E. M. C. (2008, Julho/Setembro). Práticas educativas parentais e seus efeitos na criação dos filhos. Psicologia Argumento, 26(54), 233-244.

Melnick T, Atallah A. N. (2011). Psicologia baseada em evidências: provas científicas da efetividade da psicoterapia. São Paulo: Santos.

Murta, S. G. (2007). Programas de prevenção a problemas emocionais e comportamentais em crianças e adolescentes: lições de três décadas de pesquisa. Psicologia: Reflexão e Crítica, 20, 1-8.

Murta, S. G., Leandro-França, C., Santos, K. B., \& Polejak, L. (Orgs.). (2015). Prevenção e promoção em saúde mental: fundamentos, planejamento e Estratégias de intervenção. Novo Hamburgo: Sinopsys. 
Paim, J. S. (2009). O que é o SUS? Rio de Janeiro: Editora Fiocruz.

Papalia, D. E., \& Feldman, R. D. (2013). Desenvolvimento Humano. 12a ed. Porto Alegre: AMGH.

Pardo, M. B. L., \& Carvalho, M. M. S. B. (2011). Grupo de orientação de mães no contexto de uma clínica-escola. Paidéia, 21(48), 93-100.

Paula, L. I. C., Pires, C. D., Mascarenhas, T. S., Costa, J. P. L., \& Brito, L. M. O. (2013). Percepção da associação entre estimulação ambiental e desenvolvimento normal por mães de crianças nos três primeiros anos de vida. Revista Paulista de Pediatria, 31(2), 211-7.

Pinheiro, M. I. S., \& Haase, V. G. (2012). Treinamento de cuidadores: Programas de intervenção. In M. K. Baptista, \& M. L. M. Teodoro. Psicologia de família: Teoria, avaliação e intervenção. Porto Alegre: Artmed.

Silva, J. L. G. V., Soares, E. A., Caetano, E. A., Loyola, Y. C. S., Garcia, J. A. D., \& Mesquita, G. (2011). O impacto da escolaridade materna e a renda per capita no desenvolvimento de crianças de zero a três anos. Ciências em Saúde, 1(2), 62-67.

Silva, N. C. B., Nunes, C. C., Betti, M. C. M., \& Rios, K. S. A. (2008). Variáveis da família e seu impacto sobre o desenvolvimento infantil. Temas em Psicologia, 16(2), 215-229.

Souza, P. B., Batista, A. P., \& Toni, C. G. S. (2018, Janeiro/Junho). Programa de Orientação Breve a Cuidadores de bebês: avaliação e formulação. Psi Unisc, 2(1), (pp. 106-121).

Vinha, V. H. P. (2000). O Livro da Amamentação. São Paulo: Mercado das Letras.

Zamberlan, M. A. T. (2003). Psicologia e prevenção: Modelos de intervenção na infância e na adolescência. São Paulo: EDUEL.

Weber, L. N. D. (2008). Interações entre família e desenvolvimento. In L. N. D Weber (Org), Familia e desenvolvimento: Visões interdisciplinares. (pp. 54-76). Curitiba: Jurua.

Weber, L. N. D., Viezzer, A. P., \& Brandenburg, O. J. (2003). Estilos parentais e desenvolvimento da criança e do adolescente. Palmadas e surras: ontem, hoje e amanhã. In M. Z. Brandão, F. C. S. Conte, F. S. Brandão, Y. K. Ingberman, C. B. Moura, V. M. Silva, \& S. M. Oliane (Orgs.). (2003). Sobre comportamento e cognição: A história e os avanços, a seleção por consequências em ação. (pp. 512-526). Santo André: Esetec.

Recebido em: 10/10/2018

última revisão: 06/02/2019

Aceite final: 27/03/2019

\section{Sobre as autoras:}

Pâmella Batista de Souza: Mestra em Psicologia pela Universidade Federal de Santa Catarina. Professora do Departamento de Psicologia da Universidade Estadual do Centro-Oeste. E-mail: pamella.psi@hotmail.com, Orcid: http://orcid.org/0000-0002-1720-3889

Ana Priscila Batista: Doutora em Educação pela Universidade Federal do Paraná. Professora do Departamento de Psicologia da Universidade Estadual do Centro-Oeste. E-mail: anapribatista@yahoo.com.br, Orcid: http://orcid.org/0000-0001-9849-3998

Caroline Guisantes de Salvo Toni: Doutora em Psicologia Clínica pela Universidade de São Paulo. Professora do Departamento de Psicologia da Universidade Estadual do Centro-Oeste. E-mail: carolineguisantes@yahoo.com.br, Orcid: http://orcid.org/0000-0003-2114-1964 
